\title{
"Que queres de mim, mulher?": A Virgem Maria no filme $O$ Rei dos Reis como representação de um imaginário feminino conservador
}

\author{
"What do you want of me, woman?": The Virgin Mary in the film The King of \\ Kings as a representation of a conservative female imagery
}

\section{"¿Qué quieres de mí, mujer?": La Virgen María en la película El Rey de Reyes como una representación de una imaginería femenina conservadora}

\author{
Amanda Muniz Oliveira ${ }^{1}$ \\ Helen Ulhoa Pimentel ${ }^{2}$ \\ Paulo Souto Maior Júnior ${ }^{3}$ \\ Rodolpho Alexandre Santos Melo Bastos ${ }^{4}$
}

\section{Resumo}

O presente trabalho tem por objetivo demonstrar que, embora ancorados nas figuras bíblicas tradicionais, a filmografia Cristã também faz remissão ao contexto histórico social na qual foi produzida. Partindo da análise do imaginário feminino católico, será demonstrado que, quando as representações de Maria são veiculadas no cinema, mais do que a figura bíblica em si, ali está representado o imaginário social da época na qual o filme se insere. Para tanto, foi selecionado o filme O Rei dos Reis, de 1961, que representa uma Maria extremamente conservadora, que além de seguir a tradição católica, reforça a resistência às mudanças sociais que ocorrem em seu tempo.

Palavras-chave: Virgem Maria. Imaginários Sociais. Representações Sociais.

\begin{abstract}
This work aims to demonstrate that while anchored in traditional biblical figures, the Christian filmography also makes reference to the social historical context in which it was produced. Starting from the Catholic feminine imagery analysis, it will be shown that when the representations of Mary are voiced in the film, rather than the biblical figure itself, there is represented the social imaginary of the time in which the film is inserted. To this end, it selected the film The King of Kings, 1961, which represents an extremely conservative Mary, who in addition to following the Catholic tradition, strengthens resistance to social changes taking place in his time.
\end{abstract}

\begin{tabular}{|c|c|}
\hline \multicolumn{2}{|r|}{ Acesse este artigo online } \\
\hline $\begin{array}{l}\text { QR CODE: } \\
\square<+\square \square\end{array}$ & $\begin{array}{l}\text { Website: } \\
\text { http://www.revistas.ufg.br/index.php/ci }\end{array}$ \\
\hline 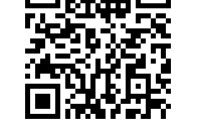 & $\begin{array}{l}\text { DOI: } \\
\text { http://dx.doi.org/10.5216/ci.v19i2.3698 } \\
1\end{array}$ \\
\hline
\end{tabular}

Keywords: Virgin Mary. Social Imaginary. Social Representation.

\footnotetext{
${ }^{1}$ Mestranda em Direito Programa de Pós-Graduação em Direito da Universidade Federal de Santa Catarina (UFSC). Brasil, Santa Catarina, Florianópolis. E-mail: amandai040@gmail.com

${ }^{2}$ Doutora em História pela Universidade de Brasília (UNB), Professora da Universidade Estadual de Montes Claros (UNIMONTES) Brasil, Minas Gerais, Montes Claros. E-mail: helenulhoa@hotmail.com

${ }^{3}$ Doutorando em História pela Universidade Federal de Santa Catarina (UFSC), Mestre em História pela Universidade Federal de Pernambuco (UFPE). Brasil, Santa Catarina, Florianópolis. E-mail: paulosoutom@gmail.com

${ }^{4}$ Mestrando em História pelo Programa de Pós-Graduação em História da Universidade Estadual de Montes Claros (UNIMONTES). Brasil, Minas Gerais, Montes Claros. E-mail: rodoxbastos@gmail.com
} 


\section{Resumen}

En este trabajo se pretende demostrar que, si bien anclado en figuras bíblicas tradicionales, toda la filmografía cristiana también hace referencia al contexto histórico-social en el que se haya producido. A partir del análisis de imágenes femeninas católica, se muestra que cuando las representaciones de María se expresan en la película, en lugar de la propia figura bíblica, se ha representado el imaginario social de la época en la que se inserta la película. Para ello, seleccionamos la película El Rey de Reyes de 1961, lo que representa una María muy conservadora, que además de seguir la tradición católica, fortalece la resistencia a los cambios sociales que tienen lugar en su tiempo.

Palabras clave: Virgen María. Social imaginario. Representaciones sociales.

\section{INTRODUÇÃO}

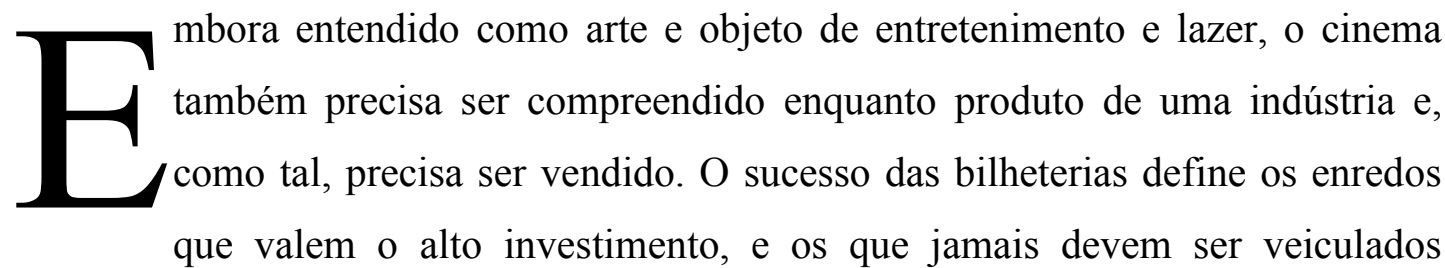

novamente. Assim, compreendendo que os filmes exibidos na grande tela, sobretudo as produções hollywoodianas, devem conquistar o seu espectador, entende-se que as representações nele veiculadas precisam encontrar respaldo no pensamento de uma sociedade. Este pensamento, que iremos denominar de imaginário, é aquilo que Michel Maffesoli (2001, p.75) entende como "uma força social de ordem espiritual, uma construção mental que se mantém ambígua, perceptível, mas não quantificável".

Os filmes hollywoodianos que retratam a vida de Jesus Cristo não fogem a esta regra do público/lucro. Mesmo quando se tratam de filmes ortodoxos, aparentemente pautados única e exclusivamente nos evangelhos do Novo Testamento, tais filmes precisam veicular, por mínimas que sejam, representações de um imaginário social, dentro de seu contexto histórico.

Levando em consideração o papel atribuído ao feminino, relegado à submissão e passividade em relação ao masculino, entende-se a existência de um imaginário social relativo às mulheres. No ocidente, este imaginário é diretamente influenciado pela Igreja Católica, que por meio das figuras canônicas de Jesus e Maria, representa modelos do que é ser homem ou mulher.

Se na própria religião existe esta definição de papéis sociais relativos ao gênero, indaga-se: é possível encontrar elementos de um imaginário mais social que canônico em filmes tradicionais sobre a vida de Cristo, no que se refere às mulheres? Mesmo seguindo fielmente a Bíblia, existiriam sutis momentos em que o imaginário deixaria o plano do social 
para ser representado no plano cinematográfico? Um filme cristão pode ser ao mesmo tempo fruto do dogma e fruto de seu tempo, ao abordar o feminino?

Para responder a tais questionamentos, faz-se necessário compreender o imaginário feminino cristão, que influenciou diretamente o modelo de conduta feminina em sociedade. Em seguida, será demonstrado como o cinema absorve e representa esse e outros imaginários. Por fim, após um breve histórico sobre os principais filmes que relatam a vida de Cristo e a forma como Maria é neles representada, será realizada uma análise no filme hollywoodiano $O$ Rei dos Reis (1961). Sucesso de bilheteria e considerado um clássico do gênero, este filme veicula as representações de uma Maria submissa e recatada, conforme os ensinamentos da Igreja Católica e que muito se aproxima do ideal feminino conservador.

Em relação à metodologia, será utilizada na análise fílmica o uso de recursos relacionados ao cinema e suas conceituações, como a importância de cortes de cenas, closeup, enquadramento, ângulos, zooms, trilha sonora, produção, iluminação e momento sócio histórico onde foram produzidos os filmes. Desta forma, o cinema será analisado como instrumento e reflexo do imaginário social vigente, servindo de veiculação para inúmeras representações.

\section{DO FRUTO PROIBIDO À ASCENSÃO AOS CÉUS: O IMAGINÁRIO FEMININO CATÓLICO}

Para compreender a representação feminina conservadora nos filmes hollywoodianos relacionados à vida de Cristo, é preciso compreender de que forma emerge o referencial feminino cristão. Tendo como ponto de partida o fato de que a religião possui participação substantiva na constituição o imaginário social, será analisada a construção da imagem da mulher a ser disseminada pela Igreja Católica. Partiremos assim, da criação de Eva.

Extraída da costela de Adão e a ele oferecida como companheira, Eva encerra em si a subordinação feminina ao masculino. Segundo Fargette (2006, p. 62): "é esse osso que correspondia exatamente ao espírito pérfido da mulher." Mesmo sendo criada do homem, a primeira mulher não resiste à tentação e é corrompida pela serpente, que a faz comer do fruto proibido por Deus. Além disso, é ela quem corrompe Adão, fazendo com que ambos sejam expulsos do paraíso, momento em que caem em desgosto com o criador.

Eva é estigmatizada e relacionada à desobediência e ao pecado. Assim, o Cristianismo utiliza sua figura para a construção ideológica da inferioridade da mulher, colocando-a como 
fonte de todo $\mathrm{mal}^{5}$. A imagem de uma mulher nascida a partir do homem é interessante para os propósitos católicos, pois auxilia a controlar a figura do feminino que até então havia gozado de certo prestígio em sociedades pagãs. Como religião patriarcal, devota de um Deus - e não de uma Deusa - a prevalência do masculino deveria ser garantida e o feminino controlado.

Embora esse controle fosse necessário, as portas do paraíso não poderiam se fechar completamente para as mulheres, sob pena de se perder fiéis. Assim, enquanto Eva absorveu todo o negativismo, tornando-se um verdadeiro modelo do que não ser, uma outra figura feminina emerge como exemplo a ser seguido: trata-se da Mãe de Cristo. É Maria quem surge como redentora para as mulheres libertando-as da maldição da queda. Conforme Macedo (2002), ela é a nova Eva; aquela que permaneceu virgem se tornando o novo ideal feminino a ser seguido.

Assim, Maria passa a ser idealizada como uma referência, um objetivo a ser alcançado. A imagem da virgem pura é a tentativa de desfalcar o Diabo na Terra, sendo ela a única privada do estigma do pecado original. Segundo Dalarum (1990, p. 39):

Numa palavra evocar Eva é já invocar Maria e significar com Jerônimo (419): "Morte por Eva, vida por Maria"; ou com Agostinho: "Pela mulher a morte, pela mulher a vida". Anselmo de Cantuária conserva este balanceamento: "Para impedir que as mulheres desesperem de alcançar a sorte dos bem-aventurados, já que uma mulher teve na origem de um mal tão grande, é preciso, para lhe restituir a esperança, que uma mulher esteja na origem de um bem igualmente grande." (DALARUM, 1990, p. 39).

O estereótipo de virgindade é uma forma de conter a sexualidade da mulher, posto que esta é propícia a incitar o caos. É controlando a sexualidade que se controla a mulher. Para Bloch (1995, p. 104):

A renúncia da carne tornou-se o princípio que fez do cristianismo uma religião verdadeiramente universal. Era 'o grande igualador'. Como Cristãos, as mulheres e os incultos podiam alcançar através da abstinência sexual uma reputação tão extraordinária quanto a de qualquer homem culto $(\mathrm{BLOCH}$, 1995, p. 104).

Bloch (1995, p. 126) ainda afirma que o caráter virginal evoca certa nostalgia pelo tempo anterior a queda; Adão e Eva antes do fruto proibido eram iguais entre si devido a ausência de sexualidade (masculino e feminino). Assim, com sua virgindade, Maria torna-se o referencial perfeito de mulher.

\footnotetext{
${ }^{5}$ Fonte de todo mal, no sentido de estarem comumente representadas como mais propícias a pecar. Conforme Sprenger e Kramer (1997), o demônio não conseguindo manipular os homens, utilizará as mulheres. Possuindo seus corpos, vão realizar todos os tipos de malefícios a humanidade. Seria por meio das mulheres que o mal entraria no mundo.
} 


\begin{abstract}
A boa Maria deu a luz a Cristo, e em Cristo deu a luz aos Cristãos. É por isso que a mãe de Cristo é a mãe dos Cristãos e manifesta-se que Cristo e os Cristãos são irmãos. Não apenas Cristo de todos os Cristãos, como é o pai de todos os homens e, principalmente, dos Cristãos". Donde a conclusão: "Pai e esposo desta virgem, ele é o seu filho". Desde época remota, Efrém e Pedro Crisólogo tinham desenvolvido a idéia de uma Maria "irmã, esposa e serva do senhor", "mãe de todos os seres que vivem pela graça", em oposição a Eva, "mãe de todos os seres que morrem pela natureza" (DALARUM, 1990, p. 42).
\end{abstract}

A mãe de Cristo com sua virgindade, vem sobrepor-se à Eva pecadora. Esta mudança aparece inclusive nas representações de Maria, como Nossa Senhora das Graças, esculpida ou desenhada com os pés sobre a cabeça de uma serpente. Conforme Swain (2006), a serpente na religião Cristã é vista como o símbolo do mal e do pecado. É a nova estrutura se alicerçando sobre o antigo. A virgem Maria tem o intento de vincular a mulher a uma nova imagem, a um novo estereótipo de mulher pura.

Compreendendo a forma como este referencial se constituiu dentro da Igreja Católica, é necessário entender de que forma ele foi absorvido pela sociedade e representado nos filmes sobre a vida de Cristo.

\title{
3 JESUS E MARIA VÃO AO CINEMA: IMAGINÁRIO E REPRESENTAÇÕES NA FILMOGRAFIA CRISTÃ
}

As relações que o cinema mantém com as noções de representações e imaginário social the permitem ser entendido como instrumento de veiculação de símbolos, crenças, opiniões, atitudes, valores, imagens, entre outros elementos que configuram uma dada realidade social e manifestação de um determinado espírito de época. Os filmes religiosos que versam sobre a vida de Cristo tratam dos pilares que edificam a sociedade ocidental, pois são concebidos de acordo com a cultura Cristã que alicerça, mas também revelam as transformações e permanências ocorridas nessa cultura, especialmente aquelas geradas pelas épocas em que os filmes foram produzidos. Neste contexto, a filmografia Cristã está repleta de sentidos, significações e representações da doutrina Católica tradicional e simultaneamente reflete as concepções próprias da época em que foi produzida.

São os elementos representacionais, através da simbolização que conferem significações aos filmes. A figura da virgem Maria é baseada no imaginário católico, mas não 
apenas; além disso, ela revela o imaginário social de cada época, manifestando as mudanças e/ou permanências operadas na imagem da mulher na sociedade.

Importante destacar que, conforme Vadico (2012), as produções fílmicas de Hollywood sobre Cristo não têm a intenção de construir uma narrativa fiel aos evangelhos canônicos. O cinema também possui seus próprios interesses, sendo um dos principais, o lucro. Não se pode esquecer que o cinema é uma arte industrial e que precisa ser comercializado. Neste mesmo diapasão, Setaro (2003) afirma que o Cristo evocado pelo cinema e pelo ocidente não reproduz integralmente o Cristo dos evangelhos. Jesus também aparece como o símbolo de uma ideia e de um pensamento vigente: reflexo direto do momento histórico vivido. Góes (2003) destaca que nele há toda uma visão de mundo, que ultrapassa o seu significado teológico. A imagem de Cristo se altera conforme os parâmetros da época em que é criada.

Isto não significa, porém, que a representação cinematográfica de Cristo é livre e descompromissada. É necessária a permanência de uma conexão com os evangelhos canônicos, pois precisam ser reconhecidos para serem aceitos. Conforme Baczko (1985, p.325:) "Os símbolos só são eficazes quando assentam numa comunidade de imaginação. Se esta não existe, eles têm a tendência a desaparecer da vida colectiva ou, então, serem reduzidos a funções puramente decorativas".

Assim como a figura de Jesus encerra em si ligações com o canônico e com o social, a figura de Maria também é representada dentro de um ethos construído e instituído pela sociedade. A mãe de Cristo é o referencial feminino a ser espelhado pelas mulheres católicas e é nela que se reflete a forma como o feminino é - ou deve ser - pensado. Maria é o símbolo feminino que traz significados, interpretações e traduções da realidade social nas quais suas produções fílmicas estão inseridas. Assim, as representações da virgem nos filmes acompanham o papel que a mulher vem exercendo na sociedade.

Neste sentido, pode-se afirmar que as representações em torno da figura de Maria são expressões de arquetípicos idealizados para as mulheres católicas. Para Cardoso (2000), essas representações possuem um caráter dinâmico, segundo o qual representar não se restringe a duplicar, repetir ou reproduzir, mas, conforme Cardoso (2012, p. 43) reconstituir, retocar "(...) mudar-lhe a constituição em um sentido que seja funcional a determinados grupos e seus interesses". A partir do momento que os filmes sobre Cristo absorvem e disseminam o contexto social e histórico nos quais se insere, eles ultrapassam a mera reprodução, pois resignificam um símbolo, ainda que ancorados no pensamento conservador. 
Desta forma, as representações refletem e produzem uma realidade, ou melhor, um imaginário. Para Pesavento (1995, p. 15) "O imaginário faz parte de um campo de representação e, como expressão do pensamento, se manifesta por imagens e discursos que pretendem dar uma definição da realidade". Os filmes de Cristo como representações sociais são tanto o produto quanto o produtor do imaginário social ocidental, fruto de sua condição e construção histórica e reflexo das mesmas representações sociais. As representações da virgem Maria, através dos filmes, traduzem as identidades sociais construídas atribuídos ao tempo histórico em que estão inseridos.

Isto posto, após breve caracterização das representações marianas no cinema Hollywoodiano, será realizada uma análise do filme $O$ Rei dos Reis, de 1961, no intuito de verificar qual a representação ali veiculada e os aspectos canônicos e sociais desta representação.

\section{4 “QUE QUERES DE MIM, MULHER?": O IMAGINÁRIO FEMININO CONSERVADOR NO CINEMA CRISTÃO}

As representações cinematográficas de Maria, embora possuam algumas variações, ancoram-se nas bases conservadoras, permanecendo fiéis aos dogmas da Igreja Católica e do imaginário social influenciado pela religião. Em filmes como A Maior história de todos os tempos $(1965)^{6}$, Jesus de Nazaré $(1976)^{7}$, Senhor dos Milagres $(2000)^{8}$ e A Paixão de Cristo $(2004)^{9}$, apenas para citar alguns, a figura da Mãe de Jesus é secundária, quase inexistindo.

Os filmes Maria de Nazareth (1995) ${ }^{10}$, Maria, em nome da Fé (1999) ${ }^{11}$, Maria, Mãe de Jesus (1999) ${ }^{12}$, são retratados de maneira muito semelhante, trazendo o drama da paixão de Cristo como tema de suas produções, de seu nascimento até a morte por meio da ótica de Maria. Mas mesmo sendo a vida de Nossa Senhora a ser contada no filme, ela ainda traz seus estigmas de passividade e recato apregoados pela doutrina católica.

No intuito de aprofundar a análise dessas representações, bem como em que medida são influenciadas pelo canônico e até que ponto encerram elementos histórico-sociais, foi escolhido como objeto de análise o clássico hollywoodiano $O$ Rei dos Reis (1961), que reafirma os estereótipos femininos de submissão e recato. Produzido por Samuel Bronston e

\footnotetext{
${ }^{6}$ Dirigido por George Stevens.

${ }^{7}$ Dirigido por Franco Zeffirelli.

${ }^{8}$ Dirigido por Helena Livanova.

${ }^{9}$ Dirigido por Mel Gibson.

${ }^{10}$ Dirigido por Jean Delannoy.

${ }^{11}$ Dirigido por Kevin Connor.

${ }^{12}$ Dirigido por Giacomo Campiotti.
} 
dirigido por Nicholas Ray, o filme é baseado nos quatros evangelhos canônicos e nos escritos do historiador romano Tácito. O filme distribuído pela Metro-Goldwyn-Mayear trata da a história de Jesus Cristo, do seu nascimento até a ressurreição.

A produção do filme O Rei dos Reis (1961) acompanha seu contexto histórico, político e social da década de 1960, nos Estados Unidos. A sociedade americana da época, no intuito de manter seus preceitos morais e religiosos, se opunha a tudo que representasse novidade, como o comunismo, ou a liberação sexual e moral. Conforme Hobsbawm (1995) a vitória da revolução chinesa, a explosão da primeira bomba atômica da URSS e a guerra da Coréia são fatores que influenciam essa rejeição do diferente. Segundo Góes (2003, p.96),

O Rei dos Reis, de Nicholas Ray, em 1961, representa esta faceta da sociedade americana, não reacionária, mas tradicional. Sociedade que tentava manter suas raízes morais, religiosas e culturais, em meio a várias transformações que ocorriam naquele momento. Em O Rei dos Reis, a figura de Cristo é extremamente sacralizada e as angulações de baixo para cima ou em primeiro plano têm como objetivo exaltar a figura do Filho de Deus. Exaltação que se verifica não somente no uso da linguagem cinematográfica mas, principalmente, na escolha do intérprete Jeffrey Hunter, louro e de olhos azuis, sublime, extraterreno. A entonação de sua voz é pomposa, teatral. Cristo é colocado acima dos mortais (Grifos no original) (GOES, 2003, p. 96).

Pertinente destacar, ainda, que durante a década de 1960 uma série de movimentos sociais emergiu trazendo suas lutas pelos direitos humanos, liberdades civis, pela paz e justiça, ecologia, etc. O movimento feminista está inserido nesse boom de contestações contra os valores vigentes, especialmente no pós-segunda guerra. De acordo com Arend (2006, p.108) nesse período da década de 1960, "em países da América do Norte e da Europa ocidental verificamos a eclosão de movimentos sociais - o Feminismo e a Contracultura - que tinham entre suas bandeiras de luta a crítica a determinadas práticas e valores da norma familiar burguesa".

Desta forma, a representação de Maria em O Rei dos Reis (1961) pode ser lida como uma reafirmação das práticas e valores da norma familiar burguesa. Mesmo durante a tensão do período que envolve a Guerra Fria e a corrida armamentista, o holocausto e os movimentos de contestações a essa postura por parte dos blocos capitalista e socialista, o filme absorve e reafirma a resistência ao novo, e a permanência da tradição. Assim, os modelos de comportamentos e os papéis sociais de gênero são reproduzidos conforme o imaginário até ali vigente que traz o feminino de forma marginalizada e submissa, restrita ao ambiente 
doméstico. O homem como provedor e cabeça da família e a mulher como submissa. Segundo Rago (2004, p.31)

Ser mulher, até aproximadamente o final dos anos 1960, significava identificar-se com a maternidade e a esfera privada do lar, sonhar com um "bom partido" para um casamento indissolúvel e afeiçoar-se a atividades leves e delicadas, que exigissem pouco esforço físico e mental (RAGO, 2004, p. 31).

Assim, já na primeira aparição de Maria no filme $O$ Rei dos reis (1961), indicada na figura 1 , verificamos indícios que apontam para a representação deste imaginário canônico e social. O narrador, figura presente em toda a trama, conta que o imperador "Cesar" Augusto determinou um recenseamento, motivo pelo qual todos deveriam voltar as suas cidades de origem para cadastro, e prossegue: "Foi assim que José, um carpinteiro, foi da Galiléia a Belém com sua esposa Maria que estava grávida do Menino-Deus".

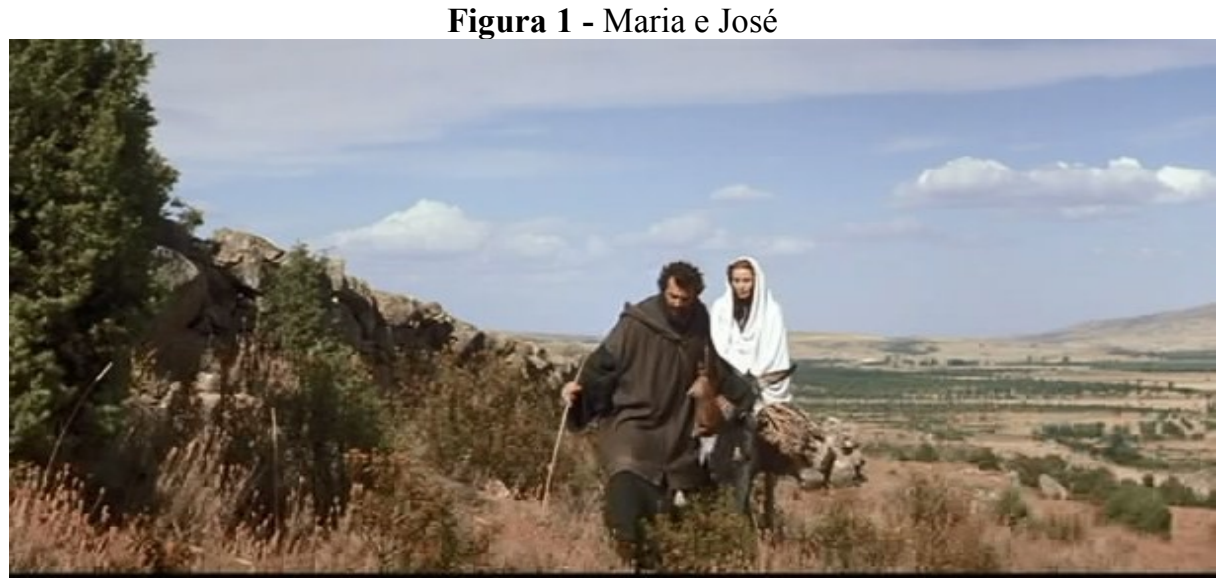

Fonte: O Rei dos Reis. Produção de Samuel Bronston, 1961 - Distribuição MGM/UA - Home Vídeo

Temos Maria, interpretada pela atriz Siobhan McKenna, envolta em um manto branco, e acompanhada por José, que é interpretado pelo ator Gérard Tichy. O manto parece fazer alusão aos seus estereótipos de pureza e virgindade ${ }^{13}$. Interessante destacar que o narrador menciona primeiramente José e só depois faz alusão à Maria, não a tratando pelo nome, mas apenas pela adjetivação de esposa grávida de Jesus, como um recipiente que carrega algo valioso. Com isso, faz-se referência a uma das funções destinadas a mulher pela tradição Judaico-Cristã, a de esposa que ao seu marido deve obediência.

Na segunda aparição de Maria, além do manto, tem-se uma vestimenta azul. Dessa forma, segundo Ana Karina Miranda de Freitas (2007, p.6-7-8), entende-se que o

\footnotetext{
${ }^{13}$ Pois conforme os ensinamentos da Igreja, mesmo grávida Maria manteve-se virgem até o fim de seus dias, pois foi receptáculo do filho de Deus, fruto de obra divina e não de conjunção carnal. Lembrando que a imagem da virgem pura e recatada é a tentativa de desfalcar o diabo no mundo, sendo ela a única privada do estigma do pecado original, sendo o modelo feminino, capaz de levar esperança, salvação e redenção às mulheres. Ela representa a forma de vida e conduta moral idealizada, modelo que deve ser espelhado pelas filhas de Eva.
} 
branco remete "a casamento [...], limpeza, paz, pureza, alma, divindade [...]. O Azul: feminilidade [...] verdade, afeto, paz, advertência, serenidade, espaço, infinito, fidelidade, sentimento profundo".

Figura 2 - Maria esperando José

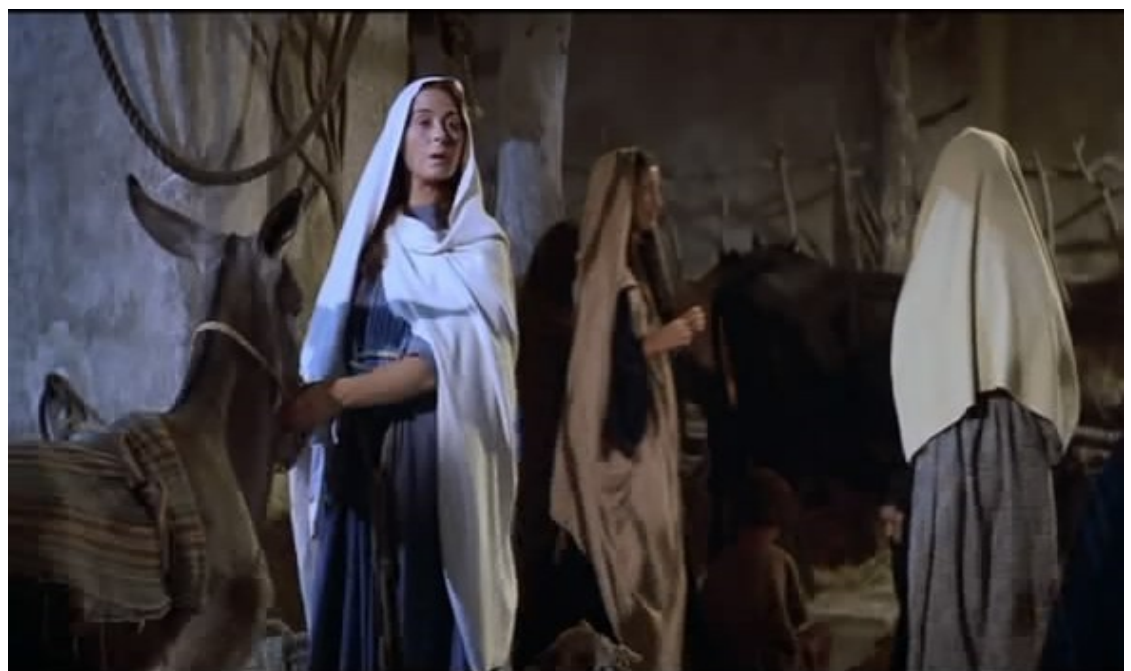

Fonte: O Rei dos Reis. Produção de Samuel Bronston, 1961 - Distribuição MGM/UA - Home Vídeo

Tudo isso confirma a forma como Maria é entendida e difundida pela tradição Católica, conforme os textos canônicos que são a base para a construção e produção do filme. $\mathrm{Na}$ próxima aparição de Maria, temos o nascimento de Jesus, em meio aos animais que ali estavam além da visita dos três reis magos.

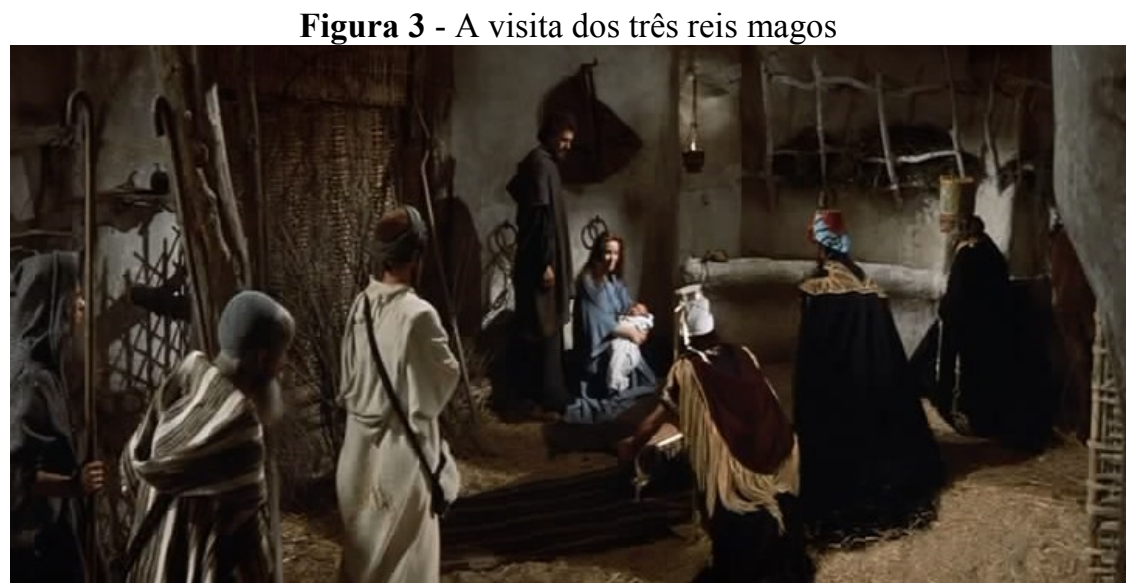

Fonte: O Rei dos Reis. Produção de Samuel Bronston, 1961 - Distribuição MGM/UA - Home Vídeo

A imagem acima está acompanhada de uma melodia e traz acordes comoventes, o que nos remete a sensação de veneração e passa a impressão de um momento que chegou e que há muito tempo estava sendo aguardado, prometido ou profetizado. Neste diapasão, Góes (2003, p.97) afirma que, 
Destaca-se no filme, a trilha sonora do húngaro Miklos Rosza, que acompanha toda a história, pontuando os momentos de maior dramaticidade com acordes que refletem e evocam sublimidade. Cristo é glorificado não só pela linguagem utilizada por Ray como também pela introdução musical de Rosza (GOÉS 2003, p. 97).

Reverencia-se ao menino-Deus e sua família, ao mesmo tempo em que Maria atende a tradição dogmática da maternidade, com expressão e atuação materno-fraterna. Nesse momento, seu manto branco passa a envolver Jesus - cena emblemática, pois Jesus herda de sua mãe uma característica que tornará Maria o contraponto de Eva e modelo a ser seguido pelas mulheres Cristãs. Assim como a humanidade carrega a mácula do pecado original, herança do casal expulso do paraíso, Jesus se livra dessa maldição, graças a sua Mãe que o concebeu longe do pecado carnal sexual.

Anos depois, João Batista vai à casa de Cristo e só encontra sua Mãe, pois o mesmo se encontrava no deserto. Maria, que estava a fazer pão, cumpria assim uma função social típica atribuída às mulheres, que era cuidar do lar. Tal característica corrobora a influência do imaginário social vigente, pois a mulher deve cuidar do espaço doméstico e privado, enquanto os assuntos públicos são conferidos ao homem. Percebe-se uma certa influência do pensamento social da época, até então conservador.

João pontua que Jesus deve pregar em Jerusalém e não no deserto, mas Maria atua como porta-voz de seu filho, afirmando que quando a hora certa chegar, ele assim fará. João menciona que percebe tristeza na fala de Maria e ela responde que também fala com alegria. Destaque para as lágrimas em seus olhos, reação mais que esperada do papel social tradicional da mãe que pressente e teme a saída de casa dos filhos.

Figura 4 - Maria em casa

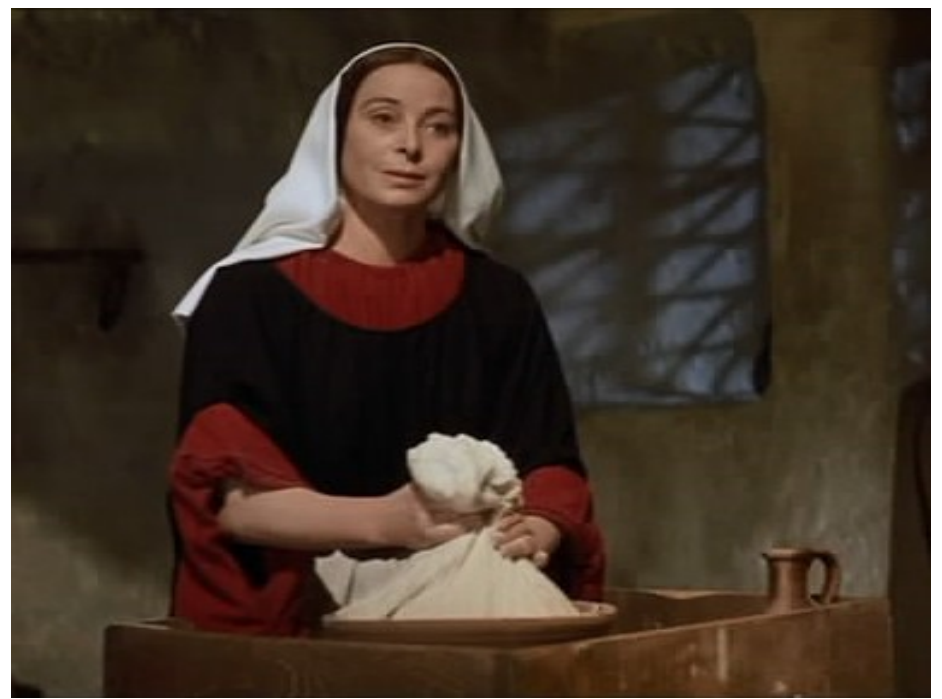

Fonte: O Rei dos Reis. Produção de Samuel Bronston, 1961 - Distribuição MGM/UA - Home Vídeo. 
Outra aparição de Maria se dá quando Madalena vai à casa de Jesus procurá-lo, contudo não o encontra, mas se depara com a sua Mãe. Imediatamente Maria se prontifica a mostrar a casa, convidando-a a sentar-se a mesa para acompanhá-la na ceia. Madalena se identifica como uma mulher do pecado, fato esse que Maria ignora, reforçando o pedido para que se sente a mesa com ela. Madalena insiste em dizer que causou muitos males e Maria a reconforta dizendo que Deus sabe que o mal existe assim como o bem, assim como a luz e a escuridão, pois o mal existe para que sejamos pessoas melhores. Madalena pede para Maria falar com Jesus em nome dela e ela responde,

Interceder? "Meu filho disse que perdendo uma ovelha entre cem não larga as outras 99 no deserto até encontrar aquela que se perdeu? E, quando a encontra, ergue-a sobre os ombros em júbilo. Quando volta para casa, junta os amigos e vizinhos e diz a eles 'Alegrai-vos pois encontrei a ovelha que havia perdido"'. Não terias procurado essa casa senão fosse a vontade de Deus. Vem e senta-se a mesa (NICHOLAS RAY, O Rei dos reis, 1961).

Nessa passagem, Maria encontra-se em seu lar e apresenta uma serenidade e cordialidade em receber Madalena, convidando-a a jantar e a reconforta com os ensinamentos de Jesus. Esse é o momento em que Maria tem maior participação e diálogo no filme. A mãe de Cristo é convidada a interceder por Madalena, a exemplo da tradição Católica, de acordo com as quais a virgem intercede junto a Jesus por seus devotos. Todavia, Maria, através do ensinamento de seu filho, reconforta Madalena, trazendo-a para dentro do seu lar, fazendo-a entender que aquele momento só está acontecendo por vontade de Deus.

Aqui se fazem necessárias algumas considerações sobre a figura de Maria Madalena. Ela demonstra a pecadora arrependida, a mulher promíscua $^{14}$ que encontra redenção ao abandonar sua vida de pecados para dedicar-se a Deus. Apesar de ser uma figura muito mais acessível às mulheres, que mesmo pecadoras como Eva e não mais virgens como Maria, necessita se aproximar da Mãe de Jesus para conseguir credibilidade. Madalena precisa se ancorar nos ensinamentos de Cristo e na figura da Maria para se estabelecer e se erguer.

\footnotetext{
${ }^{14}$ De acordo com Baldock (2009, p. 204) "Ao longo dos séculos, a imagem popular de Maria Madalena ficou tão enfeitada que a pessoa apresentada nos Evangelhos mal é reconhecida: em um extremo ela se torna a "prostituta arrependida"; no outro, a amante ou esposa de Jesus e mãe de seus filhos (...). Até onde os autores dos evangelhos se atêm, Maria Madalena pertencia ao grupo de mulheres que foram curadas por Jesus e lhe proviam sustento com seus bens pessoais, a ele e a seus discípulos.. No caso de Maria, ela foi curada de 'sete demônios"'.
}

Comun. \& Inf., Goiânia, GO, v. 19, n. 2, p. 127-145, jul./dez. 2016. 
Figura 5 - Maria e Maria Madalena

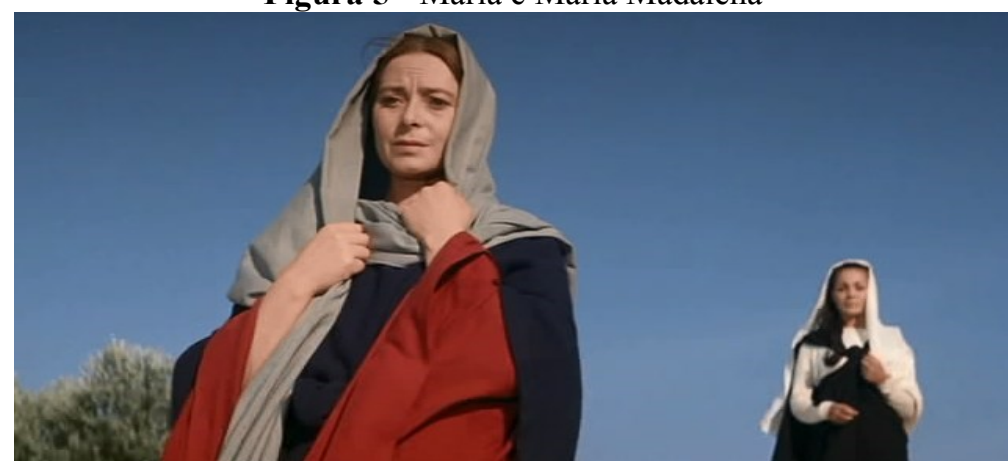

Fonte: O Rei dos Reis. Produção de Samuel Bronston, 1961 - Distribuição MGM/UA - Home Vídeo.

Maria volta a aparecer junto à multidão que acompanha o sermão de Cristo na montanha, a frente de Madalena, apresentando um semblante apreensivo, como quem pressente algo, pois é o momento que Jesus responde a uma pergunta se é o messias: "Sou o bom pastor, que sacrifica a vida por seu rebanho". Nessa passagem do filme há clara referência a ao Evangelho de João, que trás a seguinte fala de Jesus: "Eu sou o bom pastor: O bom pastor dá a vida pelas suas ovelhas. O mercenário, que não é pastor, a quem não pertencem as ovelhas, vê o lobo aproximar-se, abandona as ovelhas e foge (...)" (BÍBLIA, João, 10: 11-12).

Todavia, logo depois dessa cena do filme, em função da resposta de seu filho, Maria abaixa os olhos, fechando-os e apertando-os bem forte, como um sentimento de pesar e perda, pressentindo algo trágico - a crucificação de seu filho. Eis a representação cinematográfica daquilo que comumente se compreende como instinto materno: é amplamente difundido no imaginário social que é a mãe quem prevê os perigos e desafios a serem enfrentados por seus filhos. Nesta cena, a câmera está focada no rosto de Maria em forma de close-up ou plano fechado. Como pontua Balázs (1983, p.91) “Close-ups geralmente são revelações dramáticas sobre o que está realmente acontecendo sob a superfície das aparências".

Figura 6 - Maria, Maria Madalena, Jesus e seus discípulos

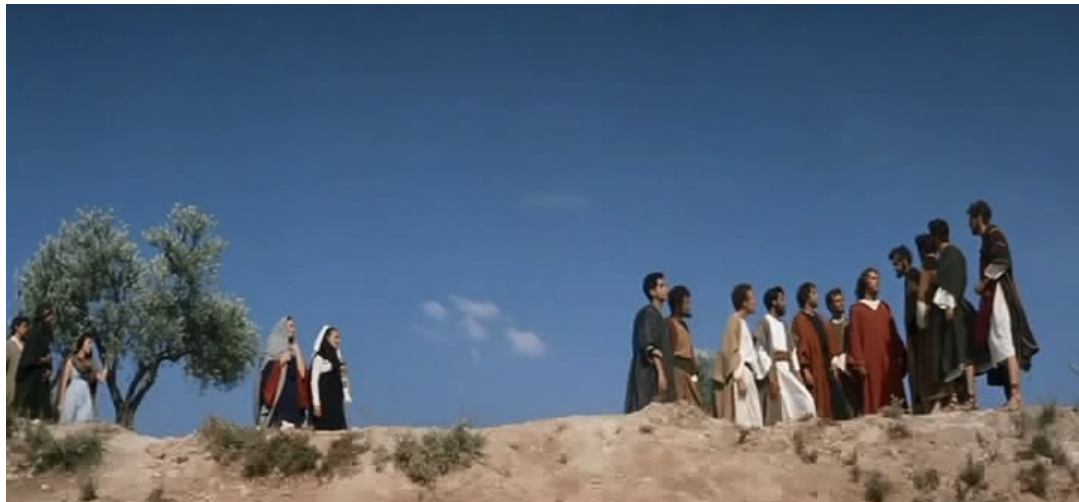

Fonte: O Rei dos Reis. Produção de Samuel Bronston, 1961 - Distribuição MGM/UA - Home Vídeo.

Comun. \& Inf., Goiânia, GO, v. 19, n. 2, p. 127-145, jul./dez. 2016. 
No fim do sermão, Maria volta a aparecer junto com Madalena, afastada de Cristo e dos discípulos. Aqui, tem-se o feminino à margem do masculino. Jesus está representado como um líder que está rodeado pelo seu grupo de apóstolos enquanto a mulher fica de longe, sem se envolver, posicionar ou reivindicar algo. Esta cena reafirma a base das organizações patriarcais, em que as decisões políticas do ordenamento social daquele grupo emanam da autoridade do homem, enquanto a mulher fica relegada a atividades secundárias e desprestigiada. Visto que a Igreja se pauta nesta ideia para conceber o modelo feminino de Maria, tem-se tanto a representação de um imaginário social quanto de um imaginário canônico.

Depois de pregar muitos meses pela Judéia, Jesus retorna à casa de sua mãe. Logo em seguida tem-se uma cena de Jesus que conserta uma cadeira, enquanto Maria enrola um novelo de lã. Em seguida, Pedro e João entram em cena, dizendo que já fizeram o que Cristo tinha pedido e que chegou a hora de partirem para Jerusalém. Jesus interrompe o conserto da cadeira e diz que ela vai ter de esperar até ele voltar e Maria rapidamente responde que a cadeira nunca será consertada. Essa resposta gera uma tensão na cena, pois Jesus demonstra surpresa com as palavras de sua Mãe. Na sequência, Maria segue com eles rumo a Jerusalém.

Figura 7 - A cadeira não será consertada

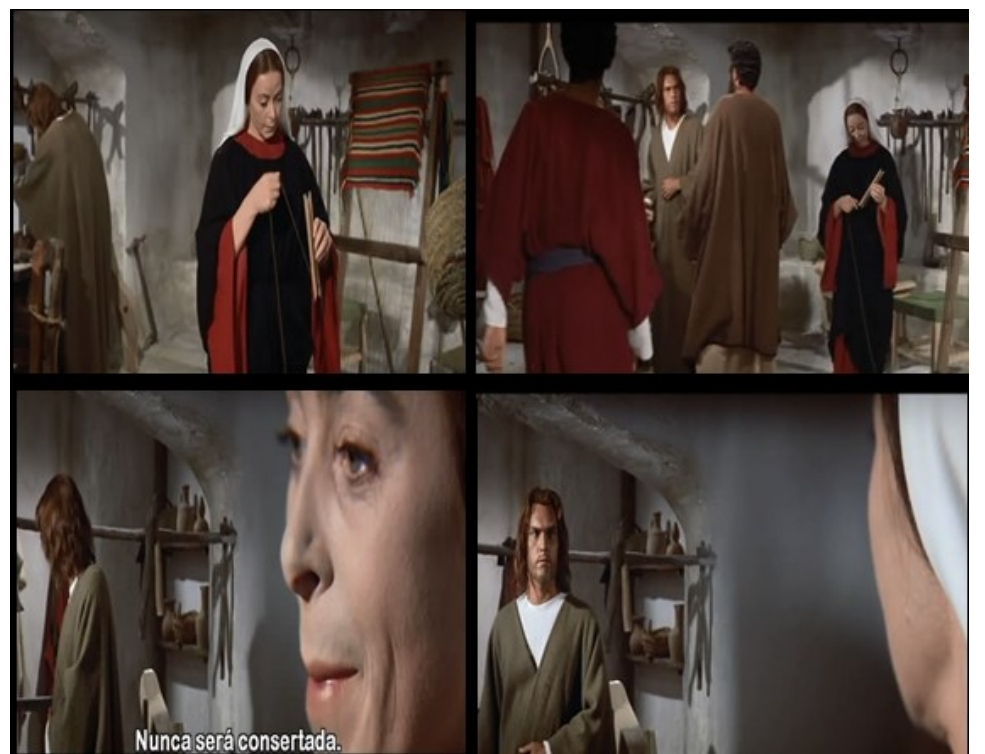

Fonte: O Rei dos Reis. Produção de Samuel Bronston, 1961 - Distribuição MGM/UA - Home Vídeo.

Temos no primeiro quadro da figura 7 (da esquerda para a direita) a relação típica de uma família tradicional: a mulher com a lã - que remete a arte do crochê ou tricô - algo relacionado a prendas do lar e o homem fazendo reparos na casa, um esforço que necessita de 
algum tipo de força bruta. Trata-se de um imaginário que reflete e produz um tipo de comportamento que por meio do cinema e dos filmes de Cristo, deixa bem definidos os papéis sociais de gênero. Maria, quando diz que a cadeira nunca mais será consertada, parece ter alguma premonição de que o filho não volta mais: um instinto materno. Trata-se qualidade entendida na sociedade ocidental como inerente a condição da mulher que nasceu para ser Mãe, outra característica da tradição patriarcal da qual o Cristianismo compartilha. Maria, nessa passagem, traz os tradicionais estereótipos de mãe e dona do lar, restrita ao ambiente doméstico, apenas observando as decisões do filho ficando à margem e em silêncio, manifestando-se apenas por meio do instinto materno.

Maria volta a aparecer quando seu filho já está carregando a cruz. Eles se encaram por um tempo e ela está claramente aflita e triste com toda aquela situação. Em seu rosto escorre uma lágrima. Ela acompanha seu filho de longe ao lado de João. Quando Jesus está sendo preparado para ser colocado na cruz, Maria aparece novamente, chorando e sendo consolada por João. Com a cruz erguida, Maria ajoelha ao seu pé e Cristo, abaixa a cabeça e diz: "Mulher, olha o teu filho", como podemos observar na imagem abaixo, e ela o encara.

Figura 8 - Jesus na cruz

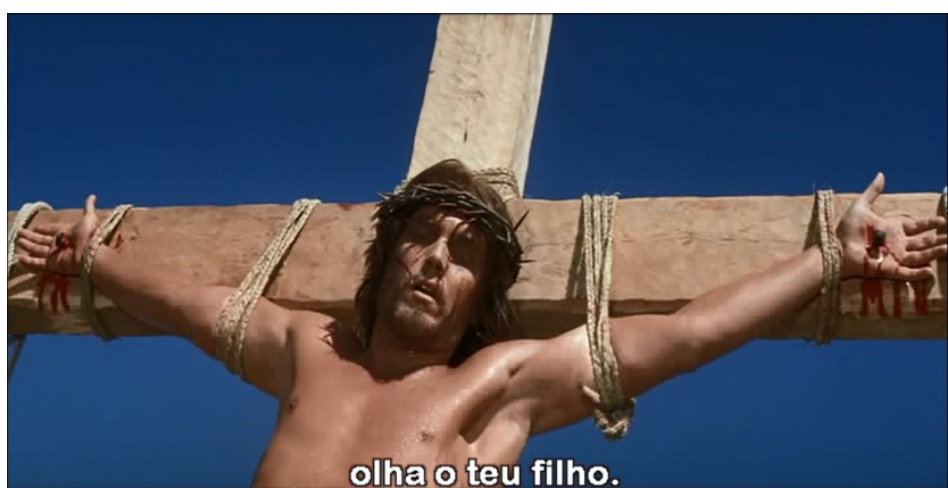

Fonte: O Rei dos Reis. Produção de Samuel Bronston, 1961 - Distribuição MGM/UA - Home Vídeo.

Interessante destacar que mesmo vendo o seu filho sofrer, Maria não perde a sua compostura. Não há gritos, desespero, desmaios e nem tentativas de alcançar Jesus. O máximo a que se permite é deixar escapar de seus olhos uma única e singela lágrima, afinal, a mulher deve ser comedida e evitar escândalos - deve manter-se reservada, mesmo em sofrimento. Em seguida, Jesus transfere a tutela de Maria, que outrora foi passada para ele devido a morte de José, seu Pai, para João. Entende-se aqui que a mulher necessita ser guardada, controlada e protegida, pois incapaz de se estabelecer sozinha, sem auxílio masculino. 
Ao pé da cruz Maria permanece até Jesus morrer. Após descerem com o corpo do filho de Deus, ele é colocado nos braço de sua mãe. Mais tarde ela acompanha os apóstolos e outras mulheres, inclusive Madalena, enquanto carregam o corpo de Jesus até o túmulo. Colocado no sepulcro e fechado, Maria e os demais vão embora.

Figura 9 - Jesus nos braços de Maria

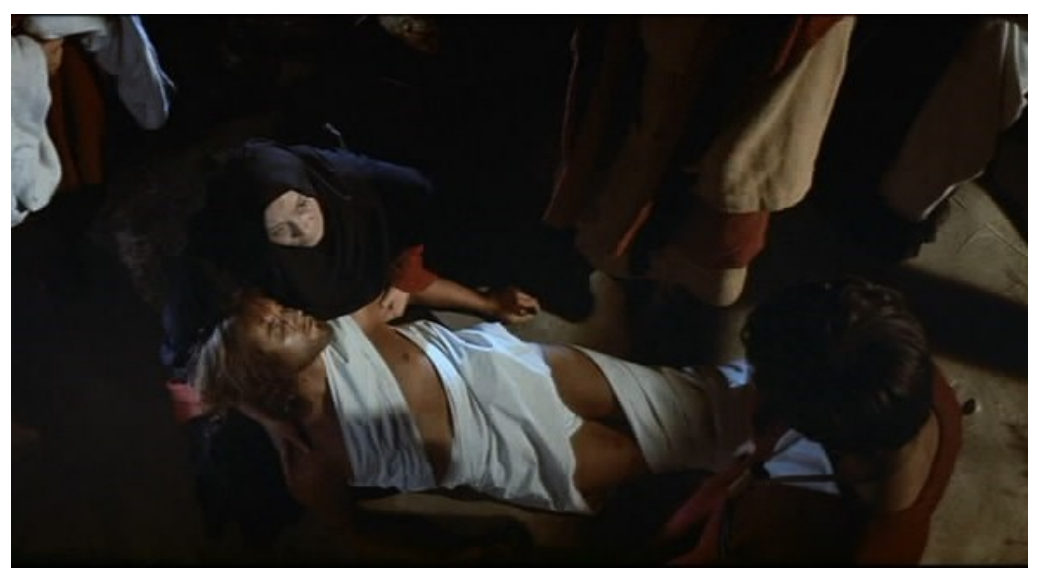

Fonte: O Rei dos Reis. Produção de Samuel Bronston, 1961 - Distribuição MGM/UA - Home Vídeo.

O filme O Rei dos reis (1961), tem Jesus Cristo como protagonista, e nele, as passagens que trazem Maria são mínimas. Nossa Senhora é sempre apresentada como esposa de José e a mãe de Cristo, colocada à margem das decisões, manifestando-se poucas vezes de maneira direta, a exemplo dos seus pressentimentos maternais. Todos esses são elementos de um imaginário conservador, composto tanto por elementos sócio-históricos quanto canônicos, que o filme reflete e produz para os espectadores da sociedade ocidental. Assim, compreendese que a combinação das passagens dos evangelhos e de elementos tradicionais referentes ao feminino - dona de casa, instinto materno, ausência de voz no cenário das decisões, compostura e comedimento dentre outros - possibilitam apontar O Rei dos Reis como mais do que um filme religioso, um filme fruto de sua época.

\section{CONSIDERAÇÕES FINAIS}

Além de objeto de lazer e entretenimento, o cinema também é um produto e como tal, precisa vender e gerar lucro à seus realizadores. Para tanto, um filme não pode se isolar do contexto histórico social no qual se insere, devendo trazer à tona temas familiares e ancorados em uma tradição de pensamento, seja para contrapô-la seja para reafirmá-la.

Os filmes hollywoodianos que retratam a vida de Jesus Cristo não fogem a esta regra. Ainda que procurem seguir fielmente o que está escrito nos Evangelhos, tais filmes precisam 
trazer elementos de imaginário social, dentro de seu contexto histórico, para conquistar público. Partindo de tal ideia, questionou-se até que ponto as representações veiculadas em um filme ortodoxo são puramente canônicas ou socialmente mistas, no que se refere à representação específica da mulher - no caso, a Virgem Maria.

Assim, demonstrou-se a constituição do imaginário feminino cristão, que influenciou diretamente o modelo de conduta feminina em sociedade. Posteriormente, esclareceu-se de que forma o cinema absorve tanto o imaginário canônico quando o social e os mescla, no intuito de gerar reconhecimento por parte do público. Por fim, após um breve histórico sobre os principais filmes que relatam a vida de Cristo e a forma como Maria é neles representada, foi feita uma análise do filme O Rei dos Reis (1961), de forma a concluir que por mais verossímel que seja em relação à tradição e ao evangelho, sutis elementos sociais e históricos estão presentes em seu bojo.

\section{REFERÊNCIAS}

A MAIOR história de todos os tempos. Produção de George Stevens. Estados Unidos: Distribuição MGM/UA - Home Vídeo, 1965.

A PAIXÃO de Cristo. Produção de Mel Gibson. Estado Unidos: Fox Filmes, 2004.

ALVES NETO, Pe. Jair Cardoso. Síntese da mariologia. Presbíteros: um site de referência para o Clero Católico, São Paulo, [s.d]. Disponível em: <www.presbiteros.com.br/site/sintesede-mariologia>. Acesso em: 16 mar. 2015.

AREND, S. M. F. Paradoxos do direito de família no Brasil: uma análise à luz da história social da família. IN: SOUZA, I., M. C. C. (Org). Casamento: uma escuta além do judiciário. Florianópolis: VoxLegem, 2006.

BACZKO, B. Imaginação social. Lisboa: Imprensa Nacional, 1985.

BALÁZS, B. A face das coisas. IN: XAVIER, I. A experiência do cinema: antologia. Rio de Janeiro: Edições Graal, 1983.

BALDOCK, J. Mulheres na Bíblia: atos heróicos, nascimentos miraculosos, confrontos, rivalidades e amor verdadeiro. São Paulo: M.Books, 2009.

BIBLIA, N.T. João. Português. Bíblia Sagrada. São Paulo: Editora Paulus, 2004. Cap.12, vers. 11.

BLOCH, R. H. Misoginia medieval: e a invenção do amor romântico ocidental. Rio de Janeiro: Editora 34, 1995.

CARDOSO, C. F. O uso, em história, da noção de representações sociais desenvolvida na psicologia social: um recurso metodológico possível. Psicologia e saber social, Rio de 
Janeiro, v. 1, n. 1, p. 40-52, 2012. Disponível em: < http://www.e-

publicacoes.uerj.br/index.php/psi-sabersocial/article/view/3244>. Acesso em: 18 mar. 2015.

CARDOSO, C. F. Uma opinião sobre as representações sociais. In: CARDOSO, C. F., MALERBA, J. (Orgs.). Representações: contribuição a um debate transdisciplinar. Campinas: Papirus, 2000, p. 9-29.

DALARUM, J. Olhares de clérigos. In: DUBY, G; PERROT, M. (Orgs.). História das mulheres no ocidente: a Idade Média. Porto: Edições Afrontamento, 1990.

Disponível em: < http://www.socine.org.br/rebeca/pdf/2_3.pdf>. Acesso em: 29 out 2014.

FARGETTE, S. Eva Lilith e Pandora o mal da sedução. Revista História Viva, São Paulo, n. $12,2006$.

FREITAS, Ana Karina Miranda de. Psicodinâmica das cores em comunicação. Nucom. Limeira/Sp Ano 4, no 12- De outubro à dezembro de 2007. Disponível em:

$<\mathrm{http}$ ://www.iar.unicamp.br/lab/luz/ld/Cor/psicodinamica_das_cores_em_comunicacao.pdf $>$. Acesso em: 22 jan. 2016.

GÓES, L. T. O mito cristão no cinema: "o verbo se fez luz e se projetou entre nós". Salvador: EDUFBA, 2003.

HOBSBAWM, E. J. Era dos extremoso breve Século XX : 1914-1991 São Paulo: Companhia das Letras, 1995.

JESUS de Nazaré. Produção de Franco Zeffirelli. Reino Unido, Itália: Lew Grade, 1977.

MACEDO, J. R. A mulher na idade média. 5. ed. São Paulo: Contexto, 2002.

MAFFESOLI, M. O imaginário é uma realidade. Revista Famecos, Porto Alegre, n. 15, 2001.

MARIA de Nazaré. Produção de Jean Delannoy. França: Citel, 1995.

MARIA, em nome da fé. Produção de Kevin Connor. Estados Unidos: Alfha Filmes, 1999. MARIA, mãe de Jesus. Produção de Giacomo Campiotti. Estados Unidos: Paulinas, 1999.

O REI dos reis. Produção de Samuel Bronstons. Estados Unidos: Distribuição MGM/UA Home Vídeo, 1961.

O SENHOR dos milagres. Produção de Helena Livanova. Rússia: Europa Filmes, 2000.

PESAVENTO, S.J. Em busca de uma outra história: imaginando o imaginário. Revista Brasileira de História, São Paulo, v. 15, n. 29, p. 9-27, 1995.

RAGO, M. Ser mulher no século XXI: ou carta de alforria. In: VENTURINI, G. et al. A mulher brasileira nos espaços público e privado. São Paulo: Editora Fundação Perseu Abramo, 2004. p. 30-42. 
SETARO, A. Prefácio. In: GÓES, L. T. O mito cristão no cinema: "o verbo se fez luz e se projetou entre nós". Salvador: EDUFBA, 2003.

SPRENGER, J.; INSTITORIS, H. O martelo das feiticeiras. 12. ed. Rio de Janeiro: Rosa dos Tempos, 1997.

SWAIN, Tânia Navarro. De Deusa a Bruxa: uma história de silêncio. Brasília: Universidade de Brasília, 1998.

FAEGETTE, Séverine. Eva, Lilith e Pandora o mal da sedução. IN: Revista História Viva: Duetto, nº12, São Paulo, 2006.

VADICO, L. O épico bíblico hollywoodiano: o espetáculo como estética da salvação. Revista Brasileira de Estudos de Cinema e Audiovisual, Rebecca, São Paulo, 2012. Dossiê, ano 1, n. 2.

Recebido em: 31/07/2015

Aceito em: 16/11/2015

Publicado em: 31/12/2016 